Aim The aim of this audit was to determine thyroid screening practices in the first year of life in children with Down syndrome in our Unit and compare them to national guidelines for the medical management of children with Down syndrome (DSMIG) .

Methods We carried out a retrospective observational charts review. Children with karyotype confirmed Down syndrome and up to one year of age were included.

Results Ten children with DS were identified and all were uncluded . Study cohort comprised 6 males and 4 females. It was noted that sux children gad no TFT done after the initial newborn screening. Out of other four, only one was on treatment for hypothyroidism, the other three had normal TFTs .

Conclusion and Recommendations It is a small retrospective audit but does reflect current clinical practice. It appears that our compliance with recommended guidelines is very low, $60 \%$ of children received no TFT after the initial newborn screening.

The clinical information which was not gathered and which could influence the frequency of testing was presence of other comorbidities like cardiac disease or Gastrointestinal disease.

Low level of adherence to screening recommendations in this audit is concerning and suggest a need to identify factors contributing to poor adherence to DSMIG guidelines for medical management of children with Down syndrome.

Broad dissemination of guidelines, frequent clinical reminders and similar auditing activities for quality assurance are important in improving adherence to clinical guidelines.

\section{P193 QUALITY IMPROVEMENT IN NURSING CLINICAL HANDOVER}

Emma Holohan*. Childrens Hospital Group Temple St, Dublin, Ireland

\subsection{6/archdischild-2019-epa.548}

Quality Improvement in Nursing Clinical Handover

Nursing Clinical handover $(\mathrm{CH})$ is a crucial point of vulnerability in patient care that can lead to errors and/or adverse events if incomplete or inaccurate (Department of health 2015, Manias et al 2016).The Department of Health clinical guidelines for $\mathrm{CH}$ (2015) key recommendations are use of a communication tool such as ISBAR3 (identify, situation, background, assessment, recommendation, readback, risk), involve patient/carer and verbal handover with written documentation. A literature search regarding research into nursing clinical handover yielded multiple articles supporting these recommendation but no gold standard process identified yet. Many research methods were used to evaluate $\mathrm{CH}$ both qualitative and quantitative.

A change to existing process was necessary to improve timeliness of process, increase efficiency and effectiveness of handover, reduce risk of errors associated with clinical handover, promote interaction during handover as per the national guidelines and to involve parents/patients in handover as per national guidelines

A new 3 step $\mathrm{CH}$ process, based on the national guidelines and up to date research literature, was introduced on a surgical ward specialising in neurosurgery and craniofacial surgery in Temple Street Children's University Hospital, Dublin in Feb 2108 following an audit of previous practice. Subsequent audit and staff survey identified the benefits of the new process which has since been implemented by other wards in the hospital

The new $\mathrm{CH}$ process has succeeded in implementing the national guidelines and is a quality improvement project that addresses patient safety, reduction in medication errors, improvements in metrics data, facilitates 'hello my name is', and use of the communication tool ISBAR 3. It improves communication with patients and families and also improves time management as nurses can finish on time and reduces by $50 \%$ the time a nurse is away from patients for handover.

1. One to one handover in quiet area (incl any undergrad or supernumerary students as per allocated area)

2. Bedside review of each patient with both commencing and finishing nurse

3. Group handover in office with all staff

\section{P194 SIGNS IN PAEDIATRIC RADIOLOGY; AN INTERACTIVE PICTORIAL REVIEW FOR PAEDIATRIC CLINICIANS}

${ }^{1}$ Simon Clifford*, ${ }^{2}$ Anna Smyth, 'Zoe Hutchinson. 'St. Vincent's University Hospital, Dublin, Ireland; ${ }^{2}$ British Columbia Children's Hospital, Vancouver, Canada

\subsection{6/archdischild-2019-epa.549}

Purpose Radiology is an important facet in the management of child health. Timely recognition of diagnoses on imaging is necessary to enable initiation of appropriate therapies. In this presentation, a wide selection of radiology signs are presented. These are a mixture of common signs which should not be missed, as well as rarer signs which can easily be misinterpreted ${ }^{1}$. The signs are presented primarily on plain film, although also using other modalities including ultrasound and $\mathrm{CT}^{2}$. The signs are displayed in such a way as to allow the viewer to quiz themselves prior to the answer being revealed. This will aid in future interpretation and understanding of paediatric imaging, for both experienced clinicians and newer trainees alike.

Methods Can you differentiate the steeple sign from the silhouette sign? Can you tell a deep sulcus sign from a continuous diaphragm sign? Do you know the scimitar sign from the snowman sign? Can you decide if it's Rigler's sign or football sign? Only after the viewer has had the opportunity to interpret the image, will the answer and explanation be revealed. For each sign, a brief overview of the radiologic features are described, along with the diagnosis and any associations. The clinical relevance of each sign is discussed ${ }^{1,2}$.

Conclusion A varied selection of paediatric radiologic signs are displayed, including neonatology, chest, cardiovascular, gastrointestinal, genitourinary, musculoskeletal and neurology. The complete list of signs will not be named in this abstract, to allow the viewer to interact with the presentation, without extensive prior knowledge. After interacting with this pictorial review, the viewer will have an increased understanding of multiple signs in paediatric radiology, which will help improve management of child health.

\section{REFERENCES}

1. Arora, R \& Kannikeswaran, N. Radiology callbacks to paediatric emergency department and their clinical impact. Pediatr Radiol 2018:48:1526. https://doi. org/10.1007/s00247-018-4176-y

2. Cogley JR, O'Connor SC, Houshyar R, Al Dulaimy K. Emergent Pediatric US: What Every Radiologist Should Know. Radiographics 2012;32:651-665. https://doi.org/ 10.1148/rg.323115111 